\title{
ESTADO DO CONHECIMENTO: A CATEGORIA EXPERIÊNCIA NO ÂMBITO DA EDUCAÇÃO FÍSICA
}

\author{
Vera Regina Oliveira Diehl \\ Universidade Federal do Rio Grande do Sul, Porto Alegre, Rio Grande do Sul, Brasil \\ Elisandro Schultz Wittizorecki \\ Universidade Federal do Rio Grande do Sul, Porto Alegre, Rio Grande do Sul, Brasil \\ Vicente Molina Neto \\ Universidade Federal do Rio Grande do Sul, Porto Alegre, Rio Grande do Sul, Brasil
}

\begin{abstract}
Resumo
Este artigo analisa as produções científicas e bibliográficas sobre a experiência e trabalho docente no âmbito da Educação Física escolar. Para análise dessas produções, observamos o debate epistemológico, a abordagem teórico-metodológica e as considerações finais. Entre as aprendizagens construídas no decorrer da revisão bibliográfica, destacamos que os conceitos apresentados por autores provenientes de diferentes concepções filosóficas contribuíram para superar a compreensão de experiência como um acúmulo temporal do sujeito diante dos acontecimentos no mundo. É possível observar que as pesquisas na área da Educação Física abordando a temática experiência, a partir de um viés epistemológico, ainda, são muito incipientes.
\end{abstract}

Palavras-chave: Educação Física. Experiência. Trabalho.

\section{Introdução}

Este texto aborda o estado do conhecimento da categoria experiência em Educação Física. O estado do conhecimento apresentado abrange um levantamento das produções científicas que pretende dar conta dos pensamentos e conhecimentos já construídos na Educação Física sobre o conceito de experiência. Assim, o objetivo deste mapeamento é identificar tendências e estabelecer um diálogo com o que vem sendo produzido sobre a temática experiência e trabalho docente no âmbito da Educação Física escolar e, assim, subsidiar a pesquisa a ser realizada.

O estado do conhecimento tem a intenção de mapear e discutir a produção científica e bibliográfica em um determinado campo de conhecimento, permitindo conhecer e identificar nas pesquisas realizadas, temáticas desenvolvidas, bem como aspectos que necessitam ser analisados e aprofundados na investigação, para possíveis avanços do tema em estudo.

Para Haddad (2002) o estado do conhecimento possibilita "num recorte temporal definido, sistematizar um determinado campo de conhecimento, reconhecer os principais resultados da investigação, identificar temáticas e abordagens dominantes e emergentes, bem como lacunas e campos inexplorados abertos à pesquisa futura" (p. 9). Nesse sentido, as ideias desse autor contribuem para sistematizar as concepções epistemológicas sobre a experiência e o mapeamento dos conhecimentos já produzidos sobre essa temática, apresentando caminhos para novas aprendizagens e avanços na construção do conhecimento. 
Portanto, apresentamos, a seguir, uma revisão bibliográfica, fundamentada em autores de perspectivas teóricas diferentes, mas, que centram suas análises na experiência como elemento indispensável para pensar a práxis educativa.

\section{Diferentes olhares sobre a categoria experiência}

Para compreender os diferentes conceitos de experiência iniciamos a discussão com as contribuições de John Dewey, tendo o pragmatismo como filosofia de base para o seu pensamento, de Edward P. Thompson, na perspectiva do materialismo histórico dialético, de François Dubet, que centra suas análises, a partir da fenomenologia, de Walter Benjamin, vinculado à tendência histórico-crítica da Escola de Frankfurt e de Hans-Georg Gadamer que fundamenta sua concepção na hermenêutica filosófica. Essa ação se justifica porque esses autores coincidem ao estender suas análises na relação entre o conceito de experiência e a educação, apresentando importantes contribuições.

No entanto, dialogar com autores de tempos históricos e olhares tão diferentes demanda compreender as singularidades que envolvem cada uma das obras aqui apresentadas, contribuindo para pensar a experiência numa perspectiva ampla. Assim, inicialmente, fizemos o exercício de compreender o que intitulamos no nosso cotidiano como experiência e, neste percurso, nos apropriar das ideias dos autores, acima mencionados, basicamente dos argumentos e princípios que sustentam o conceito de experiência. Portanto, de cada um desses autores, destacamos algumas ideias que julgamos importante para compreender o conceito de experiência.

A partir dos fundamentos concebidos pelos autores à experiência, buscamos encontrar confluência de ideias. Portanto, estabelecer um diálogo entre autores de perspectivas teóricas tão diferentes, também é um desafio que exige compreender as singularidades que abrangem as visões de mundo de cada um dos autores aqui tomados como referências. Este exercício possibilita compreender a influência e a importância que a experiência pode ter no cotidiano pedagógico e, portanto, na constituição do trabalho docente em Educação Física.

A problematização de John Dewey sobre o conceito de experiência é ampla. Portanto para iniciar uma análise e compreender o conceito de experiência, no pensamento de Dewey, em seu contexto levamos em consideração o livro Experiência e Educação ${ }^{1}$. Neste livro, o autor apresenta algumas ideias básicas para elaboração de sua teoria da experiência e suas potencialidades educacionais, que se constituem em um meio para compreender o trabalho docente no cotidiano pedagógico da Educação Física.

Dewey (2010a) procura ao longo de sua obra esclarecer como produzir uma experiência, ou seja, como conceitualizar o modo de pensar o próprio conhecimento.

O autor "chama atenção para dois princípios que são fundamentais na constituição da experiência: os princípios de interação e da continuidade" (p. 52). O princípio da interação acontece "entre um indivíduo, objetos e outras pessoas" $(p, 44)$. Já o princípio de continuidade da experiência significa que toda experiência tanto se baseia em algo existente nas experiências anteriores como modifica, de alguma maneira, "a qualidade das experiências subsequentes" (p. 37).

A proposta curricular fundamentada nas experiências comuns da vida dos estudantes é um princípio relacionado por Dewey (2010a) para direcionar a organização dos conhecimentos das disciplinas curriculares. Em suas palavras:

\footnotetext{
${ }^{1} \mathrm{O}$ título original da obra é "Experience and Education” publicada em 1938. Essa obra foi traduzida para o português por Anísio Teixeira sob o título de "Experiência e Educação", publicada em 1971.
} 
Quando a educação é concebida em termos de experiência, uma consideração se destaca em relação às demais. Tudo o que possa ser considerado como matéria de estudo, $[\ldots]$ deve derivar de materiais que, originalmente, pertençam ao escopo da experiência da vida cotidiana (p. 75).

Em síntese, a teoria de John Dewey tem relevância por ter sido um dos primeiros a dar atenção para a capacidade de pensar dos estudantes. Para esse autor todo o conhecimento é construído com base na experiência adquirida.

A contribuição do historiador inglês Edward Palmer Thompson, para o conceito de experiência é encontrada em A miséria da teoria. Nessa obra ele sistematiza o conceito de experiência, articulando-a com a perspectiva da historicidade e totalidade de todo fenômeno social.

Para Thompson (1981), compreender um processo histórico é procurar, por meio das evidências históricas, apreender como os sujeitos agem e pensam dentro de determinadas condições. Para esse autor a história é concebida como processo da vida real dos homens e das relações que estabelecem entre si, entre si e a natureza, por meio do trabalho. A totalidade implica em estabelecer relação das partes como um todo estruturado.

Para Thompson (1981) entre sujeito e objeto existe uma interação dialética no processo de construção do conhecimento que, segundo ele, se constitui a partir de dois diálogos: "[...] primeiro, o diálogo entre o ser social e a consciência social, que dá origem à experiência; segundo, o diálogo entre a organização teórica (em toda a sua complexidade) da evidência, de um lado, e o caráter determinado de seu objeto, de outro" (p. 42), ou seja, se dá no diálogo entre teoria e prática ${ }^{2}$. Vale destacar que para esse autor a experiência deve ser compreendida como práxis, que implica, também, uma reflexão tanto pessoal, quanto do grupo social.

O diálogo entre o ser social e a consciência social ocorre, por exemplo, quando o estudante constrói uma consciência de si mesmo e de sua corporeidade, a partir das ações corporais, contribuindo para o desenvolvimento da consciência social e crítica, tendo em vista sua participação na prática social.

Em síntese, a categoria experiência analisada por Thompson (1981) pode contribuir para compreender os conhecimentos construídos no trabalho docente, mas, é necessário considerar o contexto de ação, a materialidade, as condições objetivas e subjetivas e as práticas constituídas individualmente e coletivamente pelos sujeitos sociais.

François Dubet, em seu livro Sociologia da Experiência, contribui para a compreensão das experiências docentes e de socialização vivenciadas no mundo atual.

O conceito de experiência social elaborada por Dubet (1994) abrange dois aspectos importantes: práticas sociais e as lógicas de ação. Para esse autor a experiência social é crítica porque implica num trabalho reflexivo do sujeito diante do papel das normas sociais.

Portanto, entendemos que além de concretizarem a ação corporal proposta pelo docente nas aulas de Educação Física, os estudantes precisam refletir e se posicionar, criticamente sobre o que estão realizando, possibilitando-os construir e reconstruir o sentido que essas ações corporais adquire na prática social desses sujeitos.

Para Dubet (1994), a experiência social deriva da articulação das três lógicas de ação, sendo, respectivamente, a lógica da integração, estratégia e subjetivação.

Em síntese, na lógica da integração o ator é definido pelo seu pertencimento na comunidade. Já na estratégica, o ator é definido por seus interesses no mercado. Por fim, na lógica da subjetivação o ator é um sujeito crítico frente a uma sistemática de produção e dominação. Enfim, é importante enfatizar que para Dubet (1994) a experiência é subjetiva, social e também crítica.

\footnotetext{
${ }^{2}$ Entendemos que os conhecimentos pedagógicos e trabalho docente são inseparáveis, considerando que a prática deverá dar origem à teoria e essa fundamentar a prática. Sendo assim, o trabalho docente se manifesta pela maneira como as teorias pedagógicas são colocadas em ação pelo docente.
} 
Por outro lado, Walter Benjamin, filósofo alemão, associado à Escola de Frankfurt e à Teoria Crítica, no texto Experiência e Pobreza $a^{3}$ desenvolve o conceito de experiência, sugerindo que a pobreza de experiência tem atingido o mundo moderno, destacando a pobreza da experiência que os sujeitos vêm se submetendo, num mundo dominado pela informação, e pouco conhecimento.

Em Charles Baudelaire: um lírico no auge do capitalismo, Walter Benjamin apresenta as expressões "Erfahrung", como "experiência autêntica" e "Erlebnis", como "vivência". Konder (1999) contribui para elucidar esse pensamento quando diz que, "'Erfahrung' é o conhecimento obtido através de uma experiência que se acumula", é o produto do trabalho. "Erlebnis" é a vivência do indivíduo isolado, que precisa ser incorporada rapidamente e produz efeitos imediatos (p. 83) [grifo do autor].

Deste modo, as atuais condições sociais em que o conceito de experiência tal qual pressuposto por Benjamin (1989) e explicado acima por Leandro Konder, tem possibilitado ao nosso ver, somente experiências que privilegiam as vivências superficiais e efêmeras e, assim, dificulta ao sujeito experiência autêntica.

É possível pensar que na sociedade atual vem ocorrendo, tal como afirmada em 1933 por Benjamin (2012a), um empobrecimento considerável da experiência. Esse autor enuncia, na época, de modo contundente que,

[...] a horrível mixórdia de estilos e visões de mundo do século passado mostrou-nos com tanta clareza aonde esses valores culturais podem nos conduzir quando a experiência nos é subtraída, hipócrita ou sorrateiramente, que é hoje em dia uma prova de honradez confessar nossa pobreza. Sim, confessemos: essa pobreza não é apenas pobreza em experiências privadas, mas em experiências da humanidade em geral. Surge assim uma nova barbárie (p. 124-5).

A esportivização do currículo da Educação Física, no âmbito escolar, com princípios do rendimento e da competição, a nosso ver, pode contribuir para o empobrecimento da experiência. O trabalho docente em Educação Física que se fundamenta no esporte com princípios do rendimento, se limitando a incorporação de suas normas para obtenção de resultados contribui para a ausência de reflexões pedagógica no contexto escolar. A partir das ideias de Bracht (1986), de que a "busca da vitória, às vezes a qualquer custo (lucro), e do que ela representa na nossa sociedade (vencer na vida)" (p. 65) impossibilitando espaços de discussões, prevalecendo o individualismo, além de incentivar a exclusão, contribuindo para pensarmos, como já expressado, em 1933, por Benjamim (2012a), de estarmos produzindo ou vivendo uma nova barbárie, a da não experiência.

O conceito de experiência na perspectiva da hermenêutica aparece no Dicionário interdisciplinar de Hermenêutica. Ali é possível identificar a diferença entre experiência qualitativa e experiência quantitativa. Ibáñez (2004), a partir do pensamento de Aristóteles, contribui ao destacar a relação de interdependência entre a noção de experiência quantitativa e qualitativa. A experiência quantitativa é vista, por esse autor, como um sujeito especialista "peritus", podendo também ser pensado quando nos referimos a experimento, como por exemplo, uma experiência científica. A ideia de experiência qualitativa é apresenta por esse autor quando o sujeito especialista "peritus" se converte em "ex-pertus" (p. 126), com habilidades e que dominam determinados conhecimentos, a partir da prática.

Hans-Georg Gadamer é um autor, entre outros, que concebe a experiência qualitativa relacionada à arte. Gadamer (1999) discute a vivência da arte à luz da hermenêutica filosófica.

\footnotetext{
${ }^{3}$ Esse ensaio de 1933 publicado em "Magia e técnica, arte e política: ensaios sobre literatura e história da cultura" (Obras escolhidas, v. 1), lançado no Brasil pela Editora Brasiliense, na década de 1980, ganha nova edição, em 2012. Todas as citações estão feitas com base nesta edição.
} 
Para o autor na vivência da arte há um volume de significados que não pertence somente aquele conteúdo especifico ou ao objeto, mas, representa e contém a experiência de vida dos sujeitos. A qualidade para Gadamer (1999) é a integração dos novos elementos que são adicionados à experiência.

Então, considerando o que foi discutido até aqui cabe perguntar: quais as possíveis convergências e divergências entre o que pensam os autores antes mencionados sobre o conceito de experiência?

O aspecto que aproxima Dewey (2010a; 1997), Thompson (1981; 2002), Dubet (1994) e Benjamin (2012a; 2012b; 2012c), a partir de suas concepções filosóficas é que elegem a experiência como um conceito fundamental no processo educativo. O principal objetivo da escola, para Dewey (2010a), é desenvolver no sujeito "[...] a capacidade de discriminação crítica e a habilidade de raciocinar" (p. 89). Ao propor a dialética entre educação escolar e experiência, Thompson (2002), afirma que "a experiência modifica, às vezes de maneira sutil e às vezes radicalmente, todo o processo educacional, influencia os métodos de ensino, a seleção e o aperfeiçoamento dos mestres e dos currículos" (p. 13). A educação escolar, para Dubet (1994), não é apenas um espaço de reprodução, mas, também de produção, destacando os sujeitos da escola como construtores de sua própria experiência. O texto O Narrador, de Benjamin (2012b), analisa o papel da educação como constituidora de uma identidade através da troca de experiências, uma das ideias centrais do pensamento deste autor.

O processo reflexivo do sujeito é um dos aspectos que aparece tanto no pensamento de Dewey (2010a), quanto de Dubet (1994), visto que, ambos conferem como parte essencial a construção da experiência. Dewey (1997), afirma que "sem algum elemento intelectual não é possível nenhuma experiência significativa" (p. 158), já Dubet (1994) atribui significativa importância à reflexividade do sujeito, ou seja, a capacidade que esse apresenta de "dominar conscientemente, pelo menos em certa medida, a sua relação com o mundo" (p. 107).

A ideia de Dubet (1994) de que a experiência é construída socialmente pelo sujeito, a partir de suas relações sociais, a nosso ver, aproxima-se do conceito expressado por Dewey (2010a), quando destaca que a experiência humana é essencialmente social, pois, envolve comunicação e relação entre os sujeitos, revelando, desse modo, outra confluência de ponto de vista entre esses autores, que merece ser destacada.

A concepção de Thompson (1981) de que a experiência é gerada no interior das práticas e da vida material dos grupos sociais poderia indicar uma possível aproximação das ideias de John Dewey e François Dubet, se as visões de mundo, ou seja, perspectivas filosóficas não fossem tão divergentes.

Embora Walter Benjamin, Hans-Georg Gadamer e John Dewey sejam oriundos de concepções filosóficas diferentes, eles abordam a dimensão estética como experiência qualitativa. Em Benjamin (2012c) a dimensão estética está presente quando aborda a arte como uma das fontes de experiência ${ }^{4}$. No caso de Gadamer (1999) a experiência estética representa a forma de ser da própria vivência. Destaca que "a obra de arte, como tal, é um mundo para si, assim o vivenciado esteticamente, como vivência, distancia-se de todas as correlações com a realidade" (p. 131). Dewey (2010b) procura em belas artes a explicação da qualidade estética da experiência, situando-a como uma característica necessária para qualquer experiência, podendo ser chamada de "experiência de pensamento". Portanto, para esse autor, "uma experiência de pensar tem sua própria qualidade estética. Difere das experiências que são reconhecidas como estéticas, mas o faz somente em seu material" (p. 113).

\footnotetext{
${ }^{4}$ A centralidade da relação entre experiência e arte está nos escritos de Benjamin, "Experiência e pobreza"; "O narrador: considerações sobre a obra de Nicolai Leskov"; "Pequena história da fotografia"; "A obra de arte na era de sua reprodutividade técnica" são alguns textos nos quais a experiência e a estética se relacionam. Esses textos estão publicados na obra "Magia e técnica, arte e política: ensaios sobre literatura e história da cultura". 
É necessário lembrar que, embora o conceito de experiência nas perspectivas teóricas dos diferentes autores apresentados seja denso, em virtude do espaço limitado deste artigo, optamos em realizar uma síntese das ideias que consideramos relevantes para compreender a temática.

\section{Mapeamento das produções científicas em educação física}

Como as produções científicas no campo sociocultural e pedagógico da Educação Física vêm discutindo a experiência? Para responder essa questão selecionamos produções científicas recorrentes dessa área, considerando estudos cuja abordagem estivesse relacionada com a experiência e trabalho docente na Educação Física escolar. Para selecionar as publicações da área citada utilizamos os descritores: experiência, trabalho docente e educação física, utilizando como filtro o campo título, resumo e palavras-chave.

Considerando à centralidade assumida pela experiência, nesse texto, priorizamos as publicações que realizam um debate epistemológico desse conceito, descartando aquelas que apresentam um relato de experiência ou, expressam o termo "experiência" sem uma discussão conceitual específica a respeito da temática analisada.

Após uma pesquisa prévia na Base de Dados no Portal de Periódicos da Coordenação de Aperfeiçoamento de Pessoal de Nível Superior (CAPES) percebemos que a maioria dos trabalhos e artigos não esclarece o conceito de experiência ou, ainda, utilizam o termo como sinônimo de qualquer prática, levando-nos a ler, além dos resumos, o texto para identificar a experiência como categoria, motivo que nos levou a estabelecer um recorte temporal. Assim, limitamos a busca ao período compreendido entre 2004 e 2015. O critério da escolha do recorte temporal foi levado em consideração, o caráter transitório e provisório do conhecimento científico, possibilitando um repensar de concepções e teorias elaboradas em cada momento histórico-social.

Desse modo, selecionamos para esse estudo as produções científicas (artigos, dissertações e teses) disponíveis na Base de Dados da Coordenação de Aperfeiçoamento de Pessoal de Nível Superior (CAPES). Portanto, as teses e dissertações foram identificadas, a partir das informações contidas nas publicações de artigos oriundos da pesquisa cadastradas no Portal de Periódicos da Capes. Após identificar os estudos, pesquisamos nos sites da Biblioteca Digital de Teses e Dissertações dos Programas de Pós-graduação "stricto sensu" de origem destas pesquisas.

A localização de artigos em periódicos foi definida a partir da classificação do WebQualis/Capes ${ }^{5}$, pressupondo que a exigência editorial possibilitaria acesso às produções com maior profundidade e rigor científico. Revisamos periódicos nacionais avaliados, com conceitos A1, A2, B1 e B2, no campo científico da Educação Física.

O levantamento das publicações em anais de eventos científicos concentrou-se exclusivamente no Congresso Brasileiro de Ciências do Esporte (CONBRACE), de periodicidade bienal, por sua expressividade no campo acadêmico da Educação Física e por ser realizado em âmbito internacional, ou seja, levantamos trabalhos publicados - incluindo trabalhos apresentados, tanto em comunicação oral, quanto em pôsteres - em anais das três últimas edições. Os trabalhos apresentados nos Grupos de Trabalhos Temáticos "Epistemologia" (GTT 04), "Escola" (GTT 05) e "Formação Profissional e Mundo do Trabalho" (GTT 06) foram tomados como produções científicas de análise, visto que focalizam a temática proposta no estudo realizado.

\footnotetext{
${ }^{5}$ O Qualis constitui-se num sistema de avaliação de periódicos, mantido pela Coordenação de Aperfeiçoamento de Pessoal de Nível Superior (CAPES), no Brasil. Essa instituição estabelece e classifica os periodicos utilizados para a divulgação da produção cientifica dos pesquisadores e dos programas de Pós-Graduação - Mestrado e Doutorado.
} 
Dentre os trabalhos encontrados analisamos duas teses de doutorado (REZER, 2010; FIGUEIREDO, 2004) e duas dissertações de mestrado (CASTRO, 2015; LOYOLA, 2009) que tematizam a categoria experiência na área da Educação Física.

Enquanto a tese de Rezer (2010), tematiza o trabalho docente na formação inicial em Educação Física, fundamentado na hermenêutica filosófica de Hans-Georg Gadamer, a tese de Figueiredo (2004) focaliza, especificamente, a experiência social na formação docente em Educação Física, baseada na sociologia da experiência de François Dubet.

O estudo de Rezer (2010) faz referência à experiência quando afirma que a Universidade perspectiva mais do que apenas constituir um lugar de obter habilidades e competências para o exercício de uma profissão. Destaca que é "um lugar onde a experiência genuína é possível de ser encontrada, um lugar onde algo acontece conosco, algo nos modifica, nos transforma" (p. 107). O autor centra sua análise em Hans-Georg Gadamer, Martin Heidegger e Richard E. Palmer, sendo alguns dos teóricos que balizam a discussão do pesquisador. O pesquisador considera que um referencial hermenêutico poderia contribuir para redimensionar o trabalho docente e a atividade epistemológica presente na formação inicial em Educação Física.

A tese de Figueiredo (2004) busca aporte teórico nas contribuições e pensamentos de John Dewey e François Dubet, para compreender como as experiências sociais e as experiências sociocorporais dos estudantes de um curso de formação inicial em Educação Física influenciam o percurso acadêmico desses estudantes. A autora concluiu que as experiências sociais e sociocorporais anteriores e durante o processo de formação inicial de Educação Física podem determinar as ações dos estudantes no decorrer do curso, influenciando escolhas das disciplinas, bem como as relações estabelecidas com os saberes dessas disciplinas.

Em nível de mestrado, obtivemos acesso à dissertação de Castro (2015) ${ }^{6}$. Essa dissertação analisa e discute as possíveis relações entre experiência e movimento, a partir de um viés fenomenológico. A partir das ideias de Walter Benjamin, Hans-Georg Gadamer, Richard E. Palmer, Jorge Larrosa Bondía e Martin Jay realiza uma discussão sobre experiência, procurando estabelecer relação com o movimento humano. $\mathrm{O}$ autor considera a importância pedagógica de um ensino aberto às experiências nos processos de aprendizagem dos movimentos nas aulas de Educação Física.

A pesquisa realizada por Loyola (2009) apresentada como dissertação de Mestrado trata da experiência profissional e os sentidos da Educação Física. Essa investigação teve como objetivo compreender de que maneira as experiências profissionais singularizam a disciplina Educação Física no contexto escolar. François Dubet, Bernard Lahire e Claude Dubar são alguns dos autores que balizaram a discussão teórica da pesquisadora. A autora considera que a legitimidade da Educação Física na escola advém mais do potencial de apoio às demais disciplinas, seus conteúdos e organização institucional, do que dos conhecimentos específicos da área.

Na busca em periódicos da área, localizamos na Revista Movimento, cinco artigos, na Revista Portuguesa de Educação, um artigo e na Revista Pensar a Prática, um artigo, que tratam especificamente o conceito de experiência no campo da Educação Física.

Nessas revistas encontramos, além da publicação de Almeida e Fensterseifer (2011), que recorrem à hermenêutica filosófica de Gadamer para discutir o lugar da experiência e do saber da experiência como possibilidade de entender as práticas corporais no âmbito da Educação Física, seis artigos são recortes das teses de doutorado (REZER, et. al., 2012; REZER, FENSTERSEIFER e NASCIMENTO, 2011; FIGUEIREDO, 2010; 2008; 2004; e FIGUEIREDO et al. 2008) e um da dissertação de mestrado (LOYOLA; FONTES e FIGUEIREDO, 2011), totalizando oito artigos

\footnotetext{
${ }^{6} \mathrm{O}$ acesso à versão digitalizada dessa dissertação foi obtido por correio eletrônico.
} 
Nos anais do XVIII CONBRACE e V CONICE encontramos um trabalho apresentado por Fochessato; Kleinubing e Rezer (2013), no GTT "Formação Profissional e Mundo do trabalho" que analisa as produções científicas que abordam a temática "experiência dos estudantes de Educação Física no Estágio Curricular obrigatório". Os autores entendem que o estágio curricular representa lócus para o acontecimento da experiência. Buscam fundamentos nas ideias de Heidegger para entender que a experiência, como algo que nos acontece, que nos toca, que nos transforma, de imediato ou ao longo do tempo. Afirmam que a partir das experiências, os estudantes marcam "para-si" seu primeiro contato com a prática pedagógica, em um contexto escolar (p. 2) [grifo dos autores].

\section{Considerações finais}

A busca pela melhor compreensão sobre o conceito de experiência e mapeamento das produções científicas que abordam essa temática na área de conhecimento da Educação Física possibilitou algumas aprendizagens.

Entre as aprendizagens construídas no decorrer dessa revisão bibliográfica, destacamos que os conceitos apresentados por autores provenientes de diferentes concepções filosóficas provocaram reflexões que contribuíram para superar a compreensão de experiência como um acúmulo temporal do sujeito diante dos acontecimentos no mundo.

Embora, os autores apresentados, em suas construções teóricas, partem de concepções filosóficas distintas, a maioria converge para o mesmo ponto, ou seja, o interesse em problematizar a experiência como um conceito fundamental no processo educativo. Dentre os autores que problematizam a experiência no processo educativo estão, John Dewey que fundamenta a teoria da experiência ao estabelecer conexão entre experiência individual e a aprendizagem, sendo da escola, do currículo e do docente a responsabilidade de estabelecer condições à construção e reconstrução da experiência. Edward P. Thompson propõe a ideia da formação como um processo de aprendizagem subsidiado pela experiência, François Dubet reconhece a educação escolar como um espaço de reprodução e produção de experiência e Walter Benjamin faz uma reflexão sobre a importância da troca de experiências no processo educativo.

As considerações de Benjamin (2012a) de que o mundo moderno, marcado pelas tecnologias, vem causando a pobreza da experiência, talvez, pudesse acrescentar que, diante dos novos meios de informação e comunicação, da lógica do individualismo e da vida fragmentada do cotidiano, derivada das mudanças sociais na sociedade atual, tem possibilitado pensar que esse contexto vem influenciando o modo de viver, conviver e de se relacionar com outros sujeitos e, consequentemente, distanciando-se das possibilidades de experienciar os acontecimentos do seu cotidiano. É necessário considerar, ainda, que a intensidade de situações que esses sujeitos são submetidos, atualmente, tem estimulado vivências superficiais. Portanto, essa nova configuração social da atualidade pode estar contribuindo para o "empobrecimento da experiência", como bem descreveu Benjamin (2012a).

O conjunto das produções acadêmicas (dissertações e teses) analisadas permite identificar as diferentes possibilidades metodológicas da pesquisa qualitativa, em Educação Física. Nessa abordagem metodológica encontramos os estudos de Figueiredo (2004) que descreve sua pesquisa como base em alguns elementos da etnometodologia, Loyola (2008) que optou pelo estudo etnográfico, Castro (2015) caracteriza sua pesquisa como teórica, a partir de um viés fenomenológico e Rezer (2010) como sendo de natureza descritiva, pautada por uma perspectiva hermenêutica.

Portanto, a partir da revisão realizada é possível observar que as pesquisas na área da Educação Física abordando a temática experiência, a partir de um viés epistemológico, ainda são muito incipientes. 
Diante disso, pensamos na importância de produzir conhecimentos que focalizam a experiência e trabalho docente da Educação Física no contexto escolar, visto que, essa temática se torna um campo de investigação que pode, ainda, ocupar um espaço nos debates acadêmicos nas produções científicas desta área do conhecimento, ou seja, ser pesquisada e explorada com profundidade, especialmente, contribuir nas análises de como as experiências individuais, sociais e pedagógicas, sobretudo, as corporais e esportivas podem ajudar na constituição do trabalho docente da Educação Física no contexto escolar.

Entendemos que a perspectiva teórica de Thompson (1981) possibilita pensar a importância da categoria experiência como processo da formação humana, ou seja, considera as ações dos sujeitos - docentes e estudantes - no processo educativo em que estão inseridos. A experiência, a nosso ver, possibilita pensar que esse processo de formação pode ser fundamental para a organização do trabalho docente no contexto escolar, visto que influencia as diferentes dimensões do processo de ensino e aprendizagem.

\title{
STATE OF KNOWLEDGE: THE EXPERIENCE IN THE FRAMEWORK OF PHYS- ICAL EDUCATION
}

\begin{abstract}
This article analyzes the scientific and bibliographic productions on experience and teaching within Physical Education. In order to analyze these productions, we observed the epistemological debate, the theoretical and methodological approach and the final considerations. Among the learning produced during the bibliographic review, we emphasize that the concepts presented by authors from different philosophical views contributed to overcome the understanding of experience as a temporal accumulation of the individual in the face of world's events. We could see that pieces of research in Physical Education addressing epistemologically the theme experience are still very incipient.
\end{abstract}

Keywords: Physical Education. Experience. Job.

\section{ESTADO DEL CONOCIMIENTO: LA CATEGORÍA EXPERIENCIA EN EL CAM- PO DE LA EDUCACIÓN FÍSICA}

\section{Resumen}

Este artículo analiza las producciones científicas y bibliográficas sobre la experiencia y el trabajo docente en la Educación Física en el contexto escolar. Para el análisis de estas producciones, consideramos el debate epistemológico, el enfoque teórico y metodológico y las consideraciones finales. Hemos aprendido que los conceptos presentados por autores de distintos campos filosóficos han contribuido para la superación de la comprensión de la experiencia como acumulación temporal del sujeto ante los acontecimientos en el mundo. Fue posible comprender que las investigaciones en Educación Física que tratan el tema de la experiencia, desde una perspectiva epistemológica, son todavía, muy incipientes.

Palabras clave: Educación Física. Experiencia. Trabajo.

\section{Referências}

ALMEIDA, L.; FENSTERSEIFER, P. O lugar da experiência no âmbito da Educação Física. Revista Movimento, Porto Alegre, v. 17, n. 04, p. 247-263, out/dez de 2011. p. 247-263. 
BENJAMIN, W. Sobre alguns temas em Baudelaire. In: Walter Benjamin, Obras escolhidas III: Charles Baudelaire: um lírico no auge do capitalismo. São Paulo: ed. Brasiliense, 1989. p. 103-149.

BENJAMIN, W. Experiência e Pobreza. In: Magia e técnica, arte e política: ensaios sobre literatura e história da cultura. 3. ed. São Paulo: Brasiliense, 2012a. Obras Escolhidas v.1. p. 123-128.

BENJAMIN, W. O narrador. Considerações sobre a obra de Nikolai Leskov. In: Magia e técnica, arte e política: ensaios sobre literatura e história da cultura. 3. ed. São Paulo: Brasiliense, 2012b. Obras Escolhidas v.1. p. 231-240.

BENJAMIN, W. A obra de arte na era de sua reprodutibilidade técnica. In: Magia e técnica, arte e política: ensaios sobre literatura e história da cultura. 3. ed. São Paulo: Brasiliense, 2012c. Obras Escolhidas v.1. p. 179-212.

BRACHT, V. A criança que pratica esporte respeita as regras do jogo...capitalista. Revista Brasileira de Ciências do Esporte, São Paulo, v. 7, n. 2, p. 62-68, jan. 1986.

CASTRO, F. B. Experiência e movimento: possíveis desdobramentos para a Educação Física. 2015. Dissertação (Mestrado) Programa de Pós-Graduação em Educação Física. Universidade Federal de Santa Maria, Santa Maria, 2015.

DEWEY, J. Experiência e Educação. Trad. Renata Gaspar. Petrópolis, RJ: Vozes, 2010a. [Texto originalmente publicado em 1938].

DEWEY, J. Arte como Experiência. 1. ed. Trad. Vera Ribeiro. São Paulo, SP: Martins Fonte, $2010 \mathrm{~b}$.

DEWEY, J. Democracia e Educação. 4. ed. Trad. Godofredo Rangel e Anísio Teixeira. São Paulo,SP: Editora Nacional, 1997.

DUBET, F. Sociologia da experiência. Trad. de Fernando Tomaz. Lisboa: Instituto Piaget, 1994.

FIGUEIREDO, Z. C. C. Experiências Sociais no Processo de Formação Docente em Educação Física. 2004. 210 f. Tese (Doutorado em Educação). Universidade Federal de Minas Gerais. Belo Horizonte. 2004.

FIGUEIREDO, Z. C. C. Formação docente em educação física: experiências sociais e relação com o saber. Revista Movimento, Porto Alegre, v. 10, n. 1, p. 89-111, jan./abr. 2004.

FIGUEIREDO, Z. C. C. Experiências sociocorporais e formação docente em educação física. Revista Movimento, Porto Alegre, v. 14, n. 01, p. 85-110, jan/abr 2008.

FIGUEIREDO, Z. C. C. Experiências profissionais, identidades e formação docente em educação física. Revista Portuguesa de Educação, v. 23, n.2, p.153-171, 2010.

FIGUEIREDO, Z., et al. Educação física, ser professor e profissão docente em questão. Revista Pensar a Prática, no 11, n. 02. p. 209-218, 2008. 
FOCHESSATO, A., KLEINUBING, N., e REZER, R. Uma análise de produções científicas sobre as experiência dos estudantes de Educação Física no Estágio Curricular obrigatório. XVIII CONBRACE e V CONICE (2013). Brasília, DF. 2013. Disponível em: $<$ http://congressos.cbce.org.br/index.php/conbrace2013/5conice/paper/view/5080>. Acesso em: 23 ago. 2014.

GADAMER, Hans-Georg. Verdade e método I: traços fundamentais de uma hermenêutica filosófica. Tradução de Flávio Paulo Meurer. 3. ed. Petrópolis, RJ: Vozes, 1999.

HADDAD, S. (Coord.). Educação de Jovens e Adultos no Brasil (1986-1998). Série Estado do conhecimento n. 8. Brasília: MEC/Inep/Comped, 2002. Disponível em: < http://www.publicacoes.inep.gov.br/arquivos/miolo_Educ_Jovens_Adultos_Est_Conheciment o8_303.pdf >. Acesso em: 20 set. 2013.

IBÁÑEZ, J. Verbete Experiência. In: ORTIZ-OSÉS, A.; LANCEROS, P. (orgs). Dicionário interdisciplinar de hermenêutica. 4. ed. Universidad de Deusto, Bilbao, 2004.

KONDER, L. Walter Benjamin: o marxismo da melancolia 1. 3. ed. Rio de Janeiro: Civilização Brasileira, 1999.

LOYOLA, R. da C. Experiência profissional na escola e os sentidos da Educação Física. 2009. 105 f. Dissertação (Mestrado) Programa de Pós-Graduação em Educação Física do Centro de Educação Física e Desportos. Universidade Federal do Espírito Santo, Vitória, 2009.

LOYOLA, R. da C.; FONTES, S. S. D.; FIGUEIREDO, Z. C. C. Experiências profissionais e os sentidos atribuídos à Educação Física em contexto escolar. Revista Movimento. Porto Alegre, v. 17, n. 1, p. 177-193, jan/mar, 2011.

REZER, R. O trabalho docente na formação inicial em Educação Física: reflexões epistemológicas... 2010. 394 f. Tese (Doutorado). Programa de Pós-Graduação em Educação Física. Universidade Federal de Santa Catarina, UFSC, Florianópolis, 2010.

REZER, R; FENSTERSEIFER, P. e NASCIMENTO, J. Aproximações com a hermenêutica: um referencial para o trabalho docente no campo da Educação Física. Revista Movimento. Porto Alegre, v. 17, n. 02, p. 115-135, abr/jun de 2011.

REZER, R. et al. Trabalho docente na Educação Superior - reflexões epistemológicas no campo da Educação Física. Revista Brasileira de Ciências do Esporte. Florianópolis, v. 34 n. 04, p. 891-908, out./dez. 2012.

THOMPSON, E. P. A miséria da teoria ou um planetário de erros: uma crítica ao pensamento de Althusser. Rio de Janeiro: Zahar, 1981.

THOMPSON, E. P. Os Românticos: a Inglaterra na era Revolucionária. Trad. Sérgio M. R, Reis. Rio de Janeiro, RJ: Civilização Brasileira, 2002. 
Recebido em: 10/04/2016

Revisado em: 14/07/2016

Aprovado em: 19/07/2017

Endereço para correspondência:

veradiehl13@gmail.com

Vera Regina Oliveira Diehl

Secretaria Municipal de Educação de Porto Alegre, EMEF Prof ${ }^{a}$ Ana Iris do Amaral.

Av. Mário Meneghetti

Passo Pedras

91260-190 - Porto Alegre, RS - Brasil 